\title{
ON THE RELATION
}

\section{BETWEEN THE \\ CONSTITUENTS OF THE FOOD,}

AND THE

\section{SYSTEMS OF ANIMALS.}

By ROBERT DUNDAS THOMSON, M.D., LECTURER ON PRACTICAL CHEMISTRY IN THE UNIVERSITY OF GLASGOW.

Communicated by Sir B. C. BRODIE, Bart.

Received May 6th,-Read May 12th, 1846.

THE idea which is now entertained by physiologists, that the muscular part of the animal frame is derived from the albuminous constituent of the food, was clearly pointed out by Beccaria in the year 1742 (Histoire de l'Academie de Bologne, Collect. Acad. xiv. 1): he demonstrated that the flour of wheat contained two characteristic ingredients, which, on distillation or digestion, afford products totally dissimilar to each other. One of these, which he termed the starchy part, resembles in its constitution, vegetable matters, and supplies analogous products. Vegetables, he says, may be recognized by their fermenting and yielding acids, without exhibiting symptoms of putrefaction. The glutinous part of flour, on the contrary, resembles animal matter, the distinguishing feature of which is its tendency to putrefaction and conversion into a urinous (ammoniacal) liquid. "So strong," he adds, " is the resemblance of gluten to animal matter, that if we were not aware of its being extracted from wheat, we should not fail to mistake it for a product of the animal world." To convince ourselves of his thorough identification of gluten and animal muscle, it is only necessary to quote his query, "Is it not true that we are composed of the same substances which serve as our nourishment?" The same doctrine has been taught 
and practised in this country for upwards of twenty years by Dr. Prout, without any knowledge of Beccaria's views, and is now almost universally received by European physiologists, although the true authors may not always have been recognized.

With reference to the source of the fatty and oily matters which enter into the constitution of the animal system, much discussion, it is well known, has recently been carried on by Liebig and Boussingault; the former considering that they may be derived both from oil and starch, while the latter at one time was inclined to attribute the origin of fat in animals entirely to the oil contained in the food. An opportunity having lately occurred to the author, of throwing some light upon this subject, by experiments on a large scale,* the results have been condensed in the following Table, and seem to show that the oil contained in the food is by no means sufficient in amount to afford a source for animal fat.

Table I.-Table exhibiting the Amount of Oil and Wax in the Food, Dung, and of the Butter, in two Cows.

\begin{tabular}{|c|c|c|c|c|c|}
\hline Food. & $\begin{array}{l}\text { Wax } \\
\text { and } \\
\text { oil in } \\
\text { food. }\end{array}$ & Butter. & $\begin{array}{c}\text { Wax in } \\
\text { dung. }\end{array}$ & $\begin{array}{l}\text { Excess } \\
\text { of wax } \\
\text { in dung, } \\
\text { and of } \\
\text { butter. }\end{array}$ & $\begin{array}{l}\text { Excess } \\
\text { of wax } \\
\text { and oil } \\
\text { in food. }\end{array}$ \\
\hline \multirow{4}{*}{$\begin{array}{l}\text { 1.-Grass } \\
\text { 2.-Entire barley and grass } \\
\text { 3.-Entire malt and grass } \\
\text { 4.-Crushed barley, grass \& hay }\end{array}$} & $\begin{array}{c}\text { lbs. } \\
57 \cdot 36\end{array}$ & $\begin{array}{c}\text { lbs. } \\
16 \cdot 71\end{array}$ & $\begin{array}{l}\text { lbs. } \\
6 \cdot 30\end{array}$ & lbs. & $\begin{array}{c}\text { lbs. } \\
34 \cdot 35\end{array}$ \\
\hline & $39 \cdot 85$ & 10.53 & $5 \cdot 37$ & . & 23.95 \\
\hline & $34 \cdot 70$ & $11 \cdot 52$ & $4 \cdot 97$ & . . & $18 \cdot 41$ \\
\hline & $32 \cdot 16$ & $\overline{19 \cdot 10}$ & $13 \cdot 76$ & 0.70 & . \\
\hline \multirow{3}{*}{$\begin{array}{l}\text { 5.-Crushed malt and hay } \\
\text { 6.-Barley, molasses and hay } \\
\text { 7.-Crushed barley and hay }\end{array}$} & $22 \cdot 25$ & $17 \cdot 68$ & $12 \cdot 97$ & $8 \cdot 40$ & $\cdots$ \\
\hline & $14 \cdot 46$ & $11 \cdot 88$ & $8 \cdot 85$ & $6 \cdot 27$ & . . \\
\hline & $7 \cdot 68$ & $5 \cdot 22$ & $4 \cdot 27$ & $1 \cdot 81$ & $\cdots$ \\
\hline \multirow{3}{*}{$\begin{array}{l}\text { 7.-Crushed barley and hay } \\
\text { 8.-Barley, linseed and hay } \\
\text { 9.-Bean meal and hay . }\end{array}$} & $16 \cdot 75$ & 11.98 & $8 \cdot 61$ & $3 \cdot 84$ & $\because$ \\
\hline & $7 \cdot 61$ & $6 \cdot 40$ & $4 \cdot 04$ & $2 \cdot 80$ & $\cdots$ \\
\hline & $100 \cdot 94$ & $72 \cdot 26$ & 52.50 & $23 \cdot 82$ & \\
\hline
\end{tabular}

- See Report presented to the Houses of Parliament, on Feeding Cattle with Malt, 1846 ; and " Experimental Researches on the Food of Animals, \&c." 8vo. Longman, 1846. 
For the details of these experiments, see Report presented to Government on the Feeding of Cattle. For Experiment 1, see page 53 of "Experimental Researches ;" 2, ibid. p. 85 ; 3, ibid. p. 91 ; 4, ibid. 98 ; 5 , ibid. 100 ; 6, ibid. 102 ; 7, ibid. $126 ; 8$, ibid. $128 ; 9$, ibid. 130 . The manner of conducting the experiments from which these numbers have been deduced, was as follows :-

The whole of the food was accurately weighed, and the amount of wax and oil contained in it determined by extracting from a limited portion of it the quantity of matter soluble in ether; with grass it was found that 2,000 grains of grass when dried at 212 became 500 grains. This when digested in ether yielded $42 \cdot 3$ grains of a green waxy matter, which gives the per centage of wax in grass $2 \cdot 01$. Hay in the same manner, when dried and exhausted by ether, gave 2.00 per cent. of wax. All the other substances were treated in the same manner. The per centage of wax and oil contained in each was as follows :-

\begin{tabular}{|c|c|c|c|c|c|}
\hline Wax & per cent. & Oil & & & per cent. \\
\hline Rye grass & $2 \cdot 01$ & Barley & . & . & $2 \cdot 18$ \\
\hline Rye Grass Hay & $2 \cdot 0()$ & Malt & - & - & $1 \cdot 37$ \\
\hline Moist Grass dung & 0.312 & Linseed & - & . & $4 \cdot 00$ \\
\hline Moist Hay dung & $0 \cdot 600$ & Bean Meal & . & $\cdot$ & $2 \cdot 04$ \\
\hline Dry Grass ditto & $2 \cdot 67$ & & & & \\
\hline Dry Hay ditto & $3 \cdot 82$ & & & & \\
\hline
\end{tabular}

The whole of the butter was extracted from the milk by the common process of churning. The Table therefore gives the total amount of wax in the food for each experiment; the wax in the dung, which was never found to contain oil; and the butter of the milk. An example may be sufficient to explain the whole process. Two cows in 14 days consumed 1,427 lbs. each of grass $=2,854 \mathrm{lbs}$. in all. As rye grass by experiment was found to contain $2 \cdot 01$ per cent. of wax, the total amount of wax in the grass consumed will be $57.36 \mathrm{lbs}$. The two cows gave, one $343 \mathrm{lbs}$. and the other $305 \mathrm{lbs}$. of milk; the total being $648 \mathrm{lbs}$. One cow gave $180 \mathrm{oz}$. ( $11 \frac{1}{4} \mathrm{lbs}$.) of butter, and the other $130 \mathrm{oz}$. ( $8 \frac{1}{8} \mathrm{lbs}$.) of butter.-Total $=19 \mathrm{lbs} .6 \mathrm{oz}$. or $310 \mathrm{oz}$. But as butter yielded by experiment, casein 0.94, 
water $12 \cdot 79$, oil $86 \cdot 27$, it is necessary to deduct the impurity, which reduces the total oil to 16.71 lbs., as in the Table. The dung was found to contain 312 per cent. of wax; the total dung voided by the animals, being weighed, amounted in 14 days to $2,049 \frac{1}{2} \mathrm{lbs}$., and would contain $6.30 \mathrm{lbs}$. of wax. Then the last column is obtained by deducting the wax in dung and butter, from the wax in the food, $16 \cdot 71+6 \cdot 30=23 \cdot 01$ : then, 57.36 - 23.01 = 34.35 = Excess of wax in the food. (See “Experimental Researches on the Food of Animals," p. 67.)

From this Table it appears, that when grass was employed as food, there was much more wax in the food, than wax excreted and butter in the milk; but as soon as hay was substituted for the grass, the butter and the wax in the dung together exceeded the amount of oil in the grain and wax in the hay. These facts appear to demonstrate that the butter is not derived from the oil or wax; the latter in hay and grass being a green substance, bearing no resemblance to an oil. We see in the 6 latter experiments, that while the food contained about 101 lbs. of wax and oil, the dung contained $52 \frac{1}{2} \mathrm{lbs}$. of wax, or half of that contained in the food; the amount of wax and oil in the dung and butter exceeding that in the food by nearly $24 \mathrm{lbs}$., or about one-fourth part. As the experiments from which these numbers are deduced were made upon a large scale, during a period of $3 \frac{1}{2}$ months, with every attention to accuracy, we think it may be legitimately inferred that the oil of the food alone is not sufficient in amount to account for the production of oily matter in the cow.

That the systems of animals are capable of sustentation by a supply of fibrinous matter almost alone, is obvious from the history of the primitive inhabitants of the prairies of America. It is stated on good authority (Catlin) that there are 250,000 Indians who live almost exclusively on buffalo-flesh during the year. The fresh meat is cut in slices of half-an-inch in thickness across the grain, so as to have fat and lean in layers, and is hung up, exposed to the sun, and dried. Upon the food, which is pounded and eaten sometimes with marrow, the wild hordes of the West are not only nourished, but it is obvious 
that the heat of their bodies is kept up; since they taste no vegetable food whatever. Fibrin is therefore, we infer, calorifiant, $*$ or alone capable of producing animal heat. This conclusion we also deduce from the experiment in which a dog was fed for some weeks on the glutinous matter of flour (Magendie). And it may be further concluded that fibrinous or albuminous matter, when given alone, is partially converted into carbonic acid, and is removed from the system during the process of expiration. But it would appear from a consideration of the experiments which have been made on the nutrition of animals with pure fibrin, that an auxiliary in the production of animal heat is either indispensable or highly advantageous, since animals fed on fibrin alone invariably declined in health (Magendie); and the American Indians have a certain admixture of fat with their dry meat, and are in the habit likewise of using marrow with it. That the amount of calorifiant food in contradistinction tonutritive food, properly so called, as it has been well defined by Liebig, is out of all proportion greater than that required to supply the waste of the solid matter of the body, is obvious from the following Table, which represents the amount of the ultimate constituents and ash of the food of a stall-fed cow, consumed during the day.

Table II.

\begin{tabular}{|c|c|c|c|}
\hline & Fuod. & Fæces. & Consumption. \\
\hline Carbon . & $\begin{array}{l}\text { lbs. } \\
11 \cdot 90\end{array}$ & $\begin{array}{l}\text { lbs. } \\
5 \cdot 10\end{array}$ & lbs. \\
\hline Hydrogen & $1 \cdot 61$ & 0.62 & 0.59 \\
\hline Nitrogen. & 0.45 & 0.20 & 0.25 \\
\hline Oxygen . & $10 \cdot 74$ & $4 \cdot 12$ & $6 \cdot 62$ \\
\hline \multirow[t]{2}{*}{ Ash } & $1 \cdot 71$ & 1.09 & $0 \cdot 62$ \\
\hline & 26.41 & $11 \cdot 13$ & $\begin{array}{c}15 \cdot 28 ; \text { or } \\
14 \cdot 66 \text { less } \\
\text { the ash. }\end{array}$ \\
\hline
\end{tabular}

* Liebig, it is well known, divides the functions of the food into nutritive and respiratory. The author has ventured to employ instead of the latter 
The data from which this Table was constructed will be found at p. 65 of "Report," or p. 57 of "Experimental Researches on the Food of Animals." The ultimate composition of the grass and dung was determined, and the amount of the elements in each calculated as in the Table. The dung subtracted from the food gives the third column, indicating the matter taken up into the circulation of the animal.

The food in this case was grass (Lolium perenne, or rye grass). If we now calculate the amount of food which was destined for nutrition by the following formulæ, we find that it amounts only to $1.56 \mathrm{lbs}$. Albuminous matters contain about 53 per cent. of carbon, 7 of hydrogen, 16 nitrogen, and 24 oxygen: hence to obtain the carbon of the nutritive matter in the above Table, we have $\frac{.25 \times 53}{16}=0.828 \mathrm{lb}$.carbon; for the hydrogen $\frac{\cdot 828 \times 7}{53}=\cdot 109 \mathrm{lb}$. hydrogen; for the oxygen $\frac{\cdot 109 \times 24}{7}=0.373 \mathrm{lb}$. oxygen. By multiplying the nitrogen by 6.25 we obtain the total amount of nutritive matter very nearly; or, as represented in a tabular form,-

Table III.

\begin{tabular}{|lc|c|c|}
\hline & & Nutritive. & Calorifiant. \\
\hline Carbon . &. & 0.828 & 5.972 \\
Hydrogen &. & 0.109 & 0.881 \\
Nitrogen . &. & 0.250 &.. \\
Oxygen . &. & 0.373 & 6.247 \\
\hline & & 1.560 & 13.100 \\
\hline
\end{tabular}

A true system of dieting would, therefore, require such tables for each condition of animals, in order that a comparison may be instituted between the wants of the system and term the expression calorifiant or heat producing, so as to give a wider range, extending through the whole system to the function of the unazotized food, than the more local term of respiratory would appear to imply. According to this view, all food is destined for repairing the waste of the system, and for the production of animal heat. 
the food. If this mode of viewing the question be correct, then the relation of the nutritive part of the food absorbed by the animal system in the preceding experiment is to the calorifiant portion as nearly 1 to $8 \frac{1}{3}$. By comparing this fact then, which is independent of all hypotheses, with the different varieties of human food, it is probable that some light may be obtained in reference to the differences in the relative proportion of their constituents. Milk, for example, the food of the infant mammalia, contains one part of nutritive to two parts of calorifiant constituents, and in the growing state of an animal, the nutritive part of the food not only supplies the place of the metamorphosed solids, but an additional amount of it is required to increase the bulk of the individual; and as it has been already stated that animal heat is generated by the metamorphosis, or degradation of the fibrinous tissues, it is obvious that in the nourishment of infant life, there is a supply of heat from the casein vastly superior to that afforded by fibrin, to adult animals.

If we refer again to the food which is generally employed by the inhabitants of our own country, wheat and barley, we find by a mean of experiments detailed in a subsequent Table, that the average amount of albuminous matter present in them is 11 per cent., while the quantity of starch and sugar existing in these substances may vary from 70 to 80 per cent., thus affording the relation between the nutritive and calorifiant matter of 1 to 7 , and upwards. Such food, it may be inferred, is fitted for the consumption of an animal which is not subjected to much exercise of the muscular system, and may be viewed as the limit of excess of the calorifiant over the nutritive constituents of food. As the demands upon the muscular part of the frame become more urgent, the proportion of the azotized or nutritive constituents should be increased, and this may be extended until we arrive at the point where the fibrinous matter is equal to the half of the calorifiant, which is probably, in a perfectly normal physiology, the greatest relative proportion of nutritive material admissible. The proportion of the nutritive to the 
calorifiant constituents of food should therefore vary according as the animal is in a state of exercise or rest; and it is upon the proper consideration of such relations that the true laws of dieting depend. For calculations of this nature, tables exhibiting the amount of albuminous matters in the different articles of food, are indispensable, as they afford at a glance the required knowledge. The constituents of the flour used as human food are principally albuminous matter, calorifiant matter, water and salts, so that when we have determined the amount of albuminous substance in the dried condition of the flour, the remainder may be considered as calorifiant matter, without any sensible error: in the following Table the water has not been removed from the flour.

\section{Table IV.}

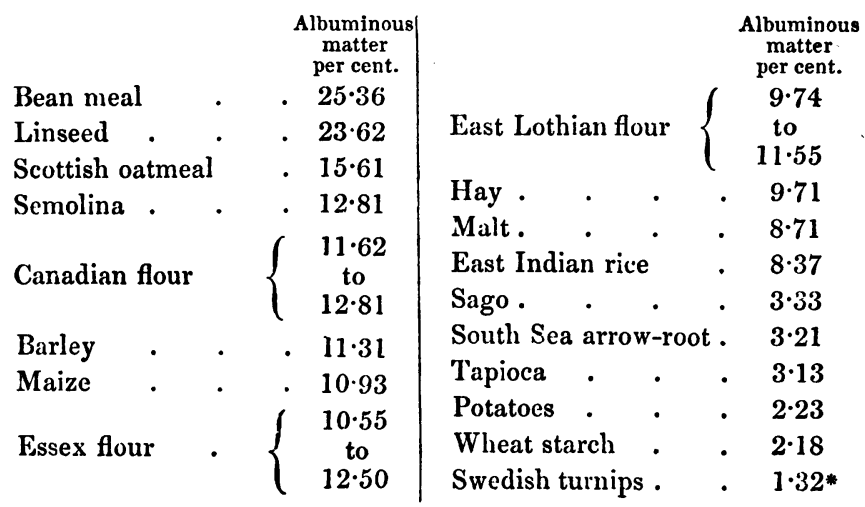

This Table is the result of experiments made by the author. The nitrogen was accurately determined in the usual manner by means of lime and soda and precipitation, as ammonia by bichloride of platinum. To obtain the amount of albuminous matter, including under the term, albumen, fibrin, casein, and

* For other experiments, see Proceedings of Philosophical Society of Glasgow, vol. i. p. 164. 
glutin, the per centage of nitrogen is multiplied by $6 \cdot 25$, the mean quantity of nitrogen in these bodies being 16 per cent. For example, beans were found by analysis to contain 4.057 per cent. of nitrogen. Now the albuminous matter in beans (albumen, fibrin, casein, and glutin) contains about 16 per cent. of nitrogen, and as $16 \times 6.25=100$, it is obvious that $4.057 \times 6.25=25.36$, the amount of albuminous matter in beans.

This Table represents the amount of albuminous matter contained in 100 parts of the various substances as they occur in commerce. As all of these substances contain from 5 to 14 per cent. of water, certain deductions are required to enable us to arrive at the true amount of calorifiant matter. In general, it may be stated that wheat flour, maize, barley, and beans, contain from 10 to 14 per cent. of water, while oatmeal contains six per cent., and tapioca, arrow-root, and sago, from 10 to 13 per cent. In order to arrive at the true amount of calorifiant matter contained in the above substances, we have only to deduct the amount of albuminous måtter in the Table with the water and salts, which, upon an average, amount together to about 12 to 15 per cent.* Then by dividing the remainder, or calorifiant matter, by the amount of albuminous substances, we obtain the relation subsisting between the nutritive and calorifiant constituents. The exceptions to the rule are obviously potatoes, turnips, and such moist bodies. In this manner tables may be constructed illustrating the true practice of dieting.

- Potatoes and turnips afford a remarkable exception to this statement. Healthy Peruvian potatoes of 1845, grown at Glasgow, yielded 72 per cent. of water, while the common potato gave as much as $78 \frac{1}{2}$ per cent. Turnips were found to contain $84 \frac{1}{2}$ per cent. of water. 


\section{Table V.}

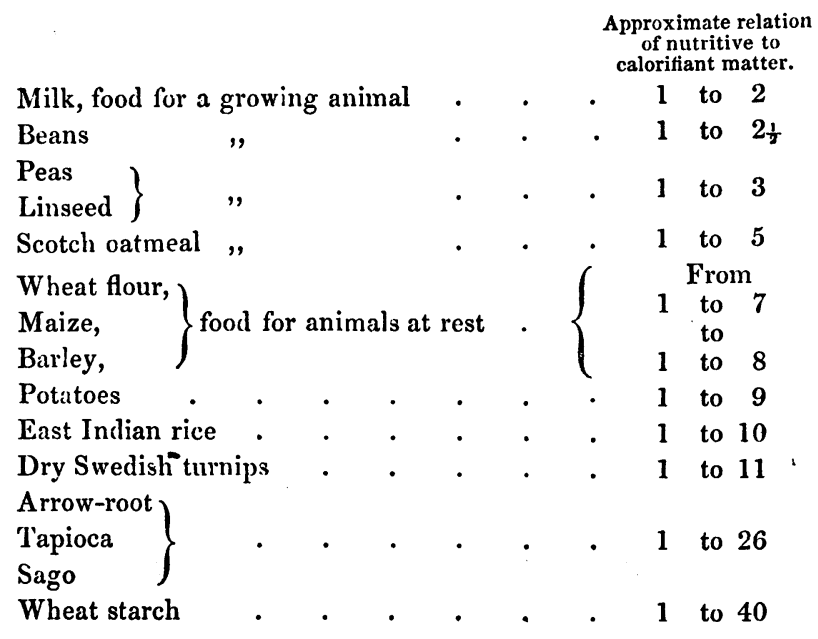

This Table is calculated as follows :-By the author's experiments, milk contains butter $3 \cdot 7$, sugar $4 \cdot 35$, casein $4 \cdot 16$, per cent. Hence, the calorifiant matter, (butter and sugan,) divided by the casein or nutritive matter, gives $8.05 \div 4.16$ $=1.93$, or very nearly in the relation of 1 to 2 . Again, to obtain the relation of nutritive matter to calorifiant matter in beans, we have, according to the approximate rule previously given, to subtract the water and salts and albuminous matter from 100 parts ; or, $12+25 \cdot 36=37 \cdot 36$ to be deducted from 100 , leaves $62 \cdot 63$ for calorifiant matter. Then, $62 \cdot 63 \div 25 \cdot 36$ $=2 \cdot 47$, or nearly in the relation of 1 nutritive to $2 \frac{1}{2}$ calorifiant. In the case of turnips and potatoes, the quantities of water being much greater, as previously stated, the calculation is somewhat different, but suggests itself at once to the reader : all very moist substances are in a similar condition. The numbers in the Table have been adopted as approximate, and have not been rigidly determined by the previous rule, because the actual numbers obtained by experiment will differ somewhat in the fractional parts by each trial. 
From this Table we are led to infer, that the food destined for an animal in a state of exercise should range between milk and wheat flour, varying in its degree of dilution with calorifiant matter, according to the nature and extent of the demands upon the system. Milk may therefore be employed with a certain amount of starchy matter, such as the class of flours, with probable advantage, as is illustrated in the milk and potatoe diet of the inhabitants of Ireland; and may also be imitated by a mixture of animal and farinaceous food; but the dilution should not exceed the prescribed limits. It is thus that we may explain the fact of beans, oats, oatmeal, and barleymeal, being used so extensively in the feeding of horses. These articles of food do not sufficiently answer alone; calorifiant matter in the form of hay should also be supplied. From this Table, likewise, we infer that as nature has provided milk for the support of the infant mammalia, the constitution of their food should always be formed on the same model. Hence we learn that milk, in some form or other, is the true food of children, and that the use of arrowroot, or any of the members of the starchy class, where the relation of the nutritive to calorifiant matter is as 1 to 26 instead of being as 1 to 2 , by an animal placed in the circumstances of a human infant, is opposed to the principles unfolded by the preceding Table. In such Tables as No. IV. it is usual to append a second column, exhibiting the equivalent value of the different kinds of food, representing, for example, 100 parts of beans as equal in nutritive power to 1160 of starch. But if the views now explained are legitimate, we see that such a method of estimating nutritive power is not founded on scientific principles. In a correct plan of dieting, the proper equilibrium must be retained between the demands of the animal organism and the constitution of the food; otherwise either the nutritive or calorifiant system must be deteriorated.

The importance of attention to the proper equilibrium of the constituents of the food is clearly pointed out in the following Table, from which it is evident that food containing vol. XXIX. 
the greatest amount of starch or sugar does not produce the largest quantity of butter, although these substances are supposed to supply the butter; but the best product of milk and butter is yielded by those species of food which seem to restore the equilibrium of the animals most efficiently; and it is also worthy of remark, that it is probably owing to the same cause that an excess of grain yields a smaller product than when a proper admixture of more calorifiant food is present.

It is obvious from this view of the subject that an animal is in a parallel condition to a soil from which a certain amount of matter is periodically removed, and which, in order to retain it in its integrity, must be replaced by an equivalent amount of material in precisely the same proportions. The food of the animal thus corresponds with the manure exhibited to the roots of the plant. To lay down therefore a proper system of dieting for all conditions of the system under exercise and rest, \&c., it would be necessary to make a series of experiments upon the animal system corresponding in extent with the analyses of the ashes of plants.

In the following Table, the first column represents the food used by two cows ; the second column gives the mean amount of milk yielded by the two animals during five days; the third exhibits the butter during periods of five days; while the fourth contains the quantity of nitrogen in the food taken by both animals during the same periods.

Table VI.

\begin{tabular}{|c|c|c|c|}
\hline & $\begin{array}{l}\text { Milk in } \\
5 \text { days. }\end{array}$ & $\begin{array}{c}\text { Butter in } \\
5 \text { days. }\end{array}$ & $\begin{array}{l}\text { Nitrogen } \\
\text { in food in } \\
5 \text { days. }\end{array}$ \\
\hline 1.-Grass & $\begin{array}{l}\text { lbs. } \\
114\end{array}$ & $\begin{array}{l}\text { lbs. } \\
3 \cdot 50\end{array}$ & $\begin{array}{c}\text { lbs. } \\
2 \cdot 32\end{array}$ \\
\hline 2.-Barley and hay . & 107 & $8 \cdot 43$ & $3 \cdot 89$ \\
\hline 3.-Malt and hay . & 102 & $3 \cdot 20$ & $3 \cdot 34$ \\
\hline 4.-Barley, molasses and hay & 106 & $3 \cdot 44$ & $3 \cdot 82$ \\
\hline 5.-Barley, linseed and hay & 108 & $3 \cdot 48$ & $4 \cdot 14$ \\
\hline 6.-Beans and hay . & 108 & $3 \cdot 72$ & $5 \cdot 27$ \\
\hline
\end{tabular}


We may infer from these results that grass affords the best products, because the nutritive and calorifiant constituents are combined in this form of food in the most advantageous relations. The other kinds of food have been subjected to certain artificial conditions, by which their equilibrium may have been disturbed. In the process of hay-making, for example, the colouring matter of the grass is either removed or altered ; a portion of the sugar is washed out or destroyed by fermentation; while certain of the soluble salts are removed by every shower of rain which falls during the curing of the hay. Perhaps similar observations are more or less applicable to the other species of food enumerated.

The principles, which it has been the object of this paper to explain, being understood, little difficulty will be experienced in constructing dietaries so as to meet the wants of the animal system under the particular circumstances in which it may be placed, either when vegetable food is alone used, or when it is desirable to employ also animal food. By various mixtures of one kind of flour less supplied with azotized matter, with another which is richer in this material, the equilibrium of the food which, from meteorological causes prevailing in any particular country, may not have reached the proper standard, may be effectually restored. The wheat flour of England, for example, is inferior to that of the continent of Europe and of America, as appears from Table IV. It may, however, be improved by an admixture either with foreign flour, or with oatmeal, barley, beans, or any of those substances which stand above it in the Table; and in this state it will be found to form a palatable and well-raised bread. All of these species of grain owe their nutritive properties to the presence of fibrin, casein, glutin, and albumen. It is in the predominance of glutin over the other azotized materials that wheat owes its superior power of detaining the carbonic acid engendered by fermentation, and thus communicating to it the vesicular, spungy structure, so characteristic of good bread. By mixing one-third of Canada flour with two-thirds of maize, a very good loaf is produced; and 
when equal parts of flour and of oatmeal, or of barleymeal, or of peasemeal, are employed, a palatable bread is the result. Beneficial effects would probably follow from the admixture of two or three different kinds of grain ; and many of these forms of bread might be substituted with advantage for pure wheat bread in peculiar conditions of the system.

The preceding observations lead to an extensive field of experiment and deductions of a highly practical nature, and may assist in indicating the direction in which the physician should pursue his inquiries when studying the laws by which the animal system is to be retained in a state of health. 